\title{
Comparative study of a concentrated photovoltaic-thermoelectric system with and without flat plate heat pipe
}

\section{Samson Shittu}

Guiqiang Li*

Guiqiang.Li@hull.ac.uk

Xudong Zhao

Xudong.Zhao@hull.ac.uk

Yousef Golizadeh Akhlagh

Xiaoli $M$

Min Yu

School of Engineering and Computer Science, University of Hull, HU6 7RX, UK

${ }^{*}$ Corresponding authors.

Abstract

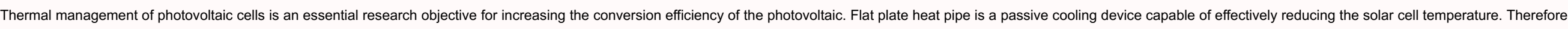

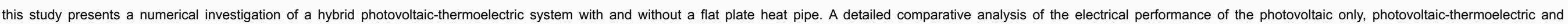

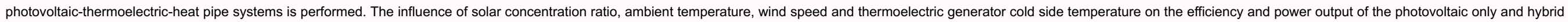

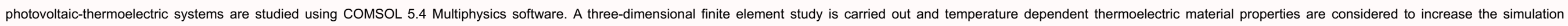

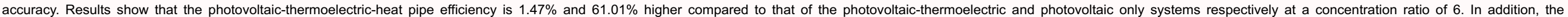

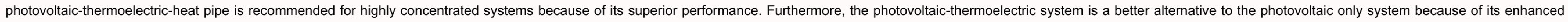

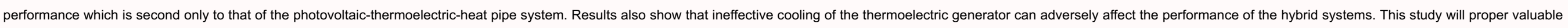

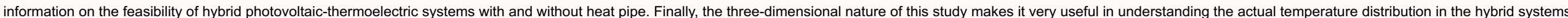

Keywords: Photovoltaic-thermoelectric; PV; Heat pipe; Thermal management; Finite element method

\section{Nomenclature}

concentration ratio

$c_{P}$

specific heat capacity, $\mathrm{J} / \mathrm{kg} / \mathrm{K}$

solar irradiance, $\mathrm{W} / \mathrm{m}^{2}$ 
molar mass, $\mathrm{g} / \mathrm{mol}$

power output, $\mathrm{W}$

$\dot{\mathrm{P}}$

power generated per volume, $\mathrm{W} / \mathrm{m}^{3}$

$p_{c}$

capillary pressure, $\mathrm{Pa}$

$p_{g}$

gravitational pressure

liquid pressure, $\mathrm{Pa}$

$p_{\text {sat }}$

saturation pressure, $\mathrm{Pa}$

$p_{v}$

vapor pressure, $\mathrm{Pa}$

$\dot{\mathrm{q}}$

volumetric energy absorption, $\mathrm{W} / \mathrm{m}^{3}$

$\rho_{v}$

vapor density, $\mathrm{kg} / \mathrm{m}^{3}$

$\mathrm{R}_{\text {in }}$

internal resistance, $\Omega$

$\mathrm{R}_{\mathrm{L}}$ 
figure of merit, $\mathrm{K}^{-1}$

\section{Greek symbols}

\section{$a$}

Seebeck coefficient, V/K

$\eta$

efficiency

$\sigma$

electrical conductivity, $S / m$

thermal conductivity, $\mathrm{W} / \mathrm{m} / \mathrm{K}$

$\rho$

density, $\mathrm{Kg} / \mathrm{m}^{3}$

$\beta$

$\mathrm{PV}$ temperature coefficient, $\mathrm{K}^{-1}$

\section{Abbreviations}

AM

air mass

$\mathrm{Bi}_{2} \mathrm{Te}_{3}$

bismuth telluride

EVA

ethylene vinyl acetate

PV

photovoltaic 


\section{Introduction}

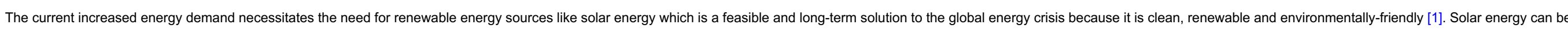

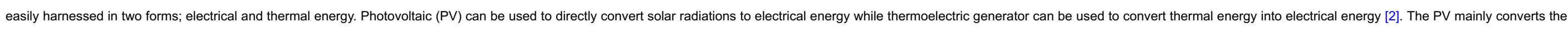

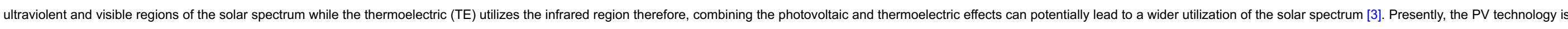

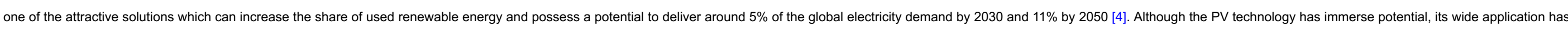

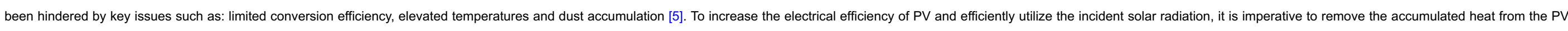
surface and utilize this waste heat appropriately [6].

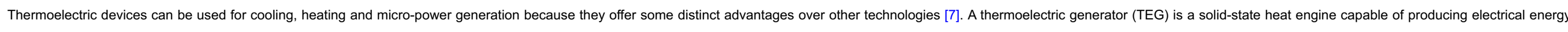

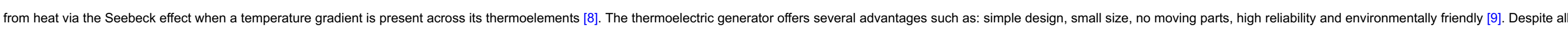

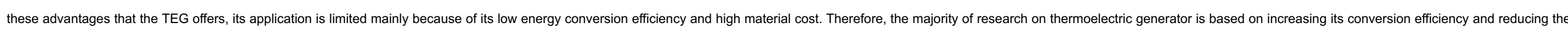

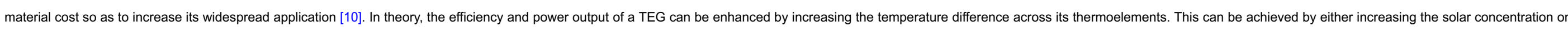

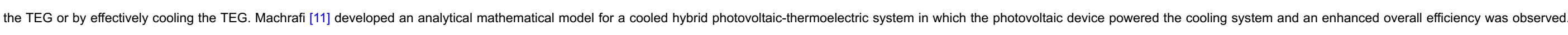

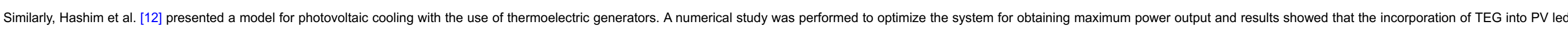
to an increase in overall power output and conversion efficiency of the hybrid system.

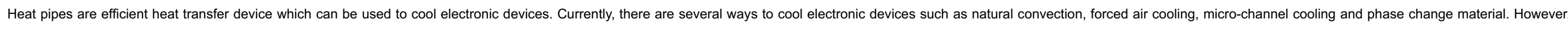

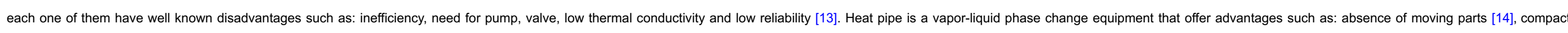

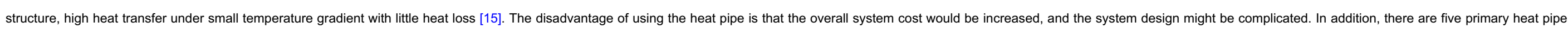




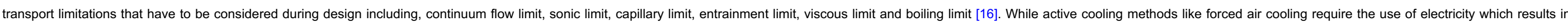

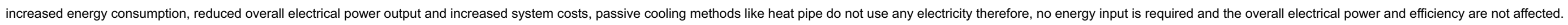

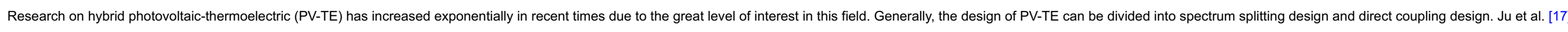

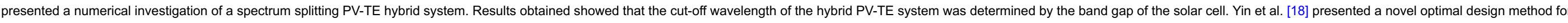
a concentrated spectrum splitting photovoltaic-thermoelectric hybrid system. They found that the optimum cut-off wavelength of the spectral splitter decreases with the increase of the thermoelectric figure of merit.

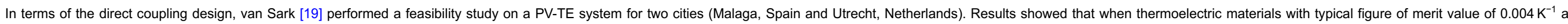

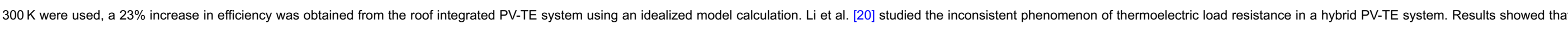
the optimum thermoelectric load resistance for maximum power output in a TE only, TE in PV-TE and PV-TE are all different.

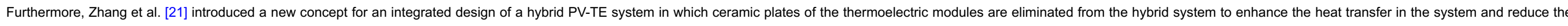

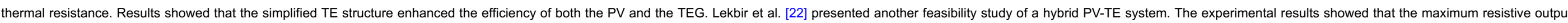

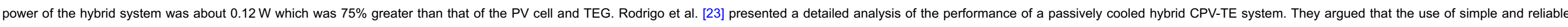

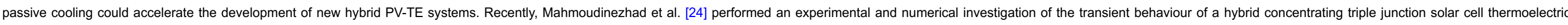
generator system. Results obtained showed that the use of TEG in a hybrid system allowed for the achievement of a more stable overall output power rather than a fluctuating power output.

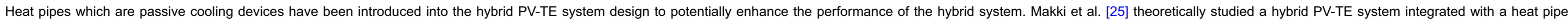

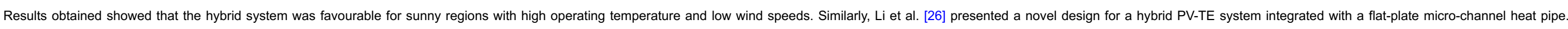

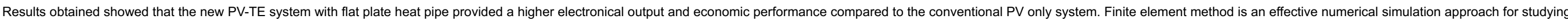

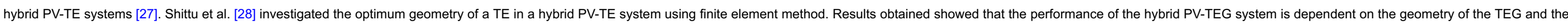
temperature coefficient value of the PV used. This finding was in agreement with Li et al. [29] who also emphasised the need for thermoelectric geometry optimization.

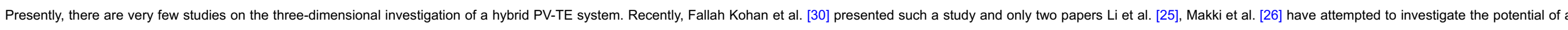

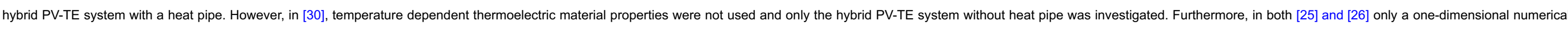

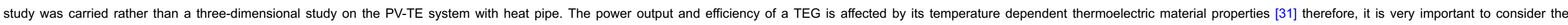

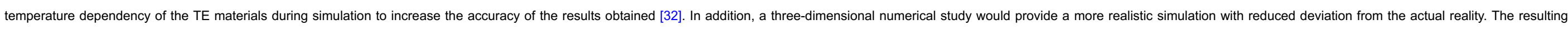
three-dimensional temperature distribution in the hybrid system would facilitate the understanding of heat transfer process in the system and enhance the performance predictions.

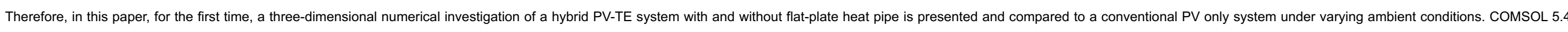

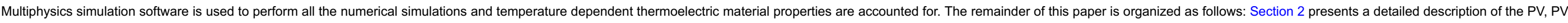

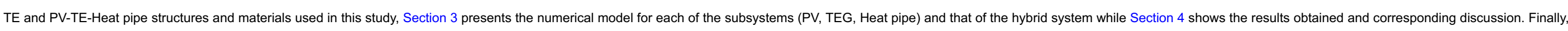
Section 5 presents the conclusions from this study.

\section{Structure description and material properties}

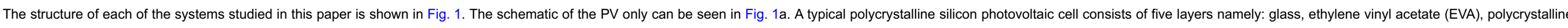

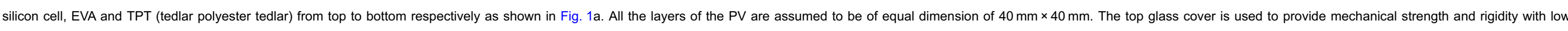

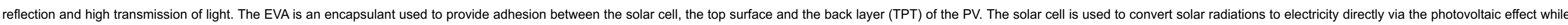

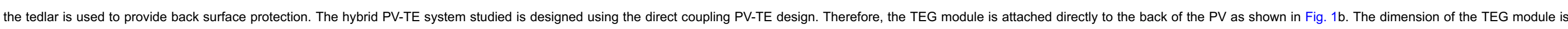

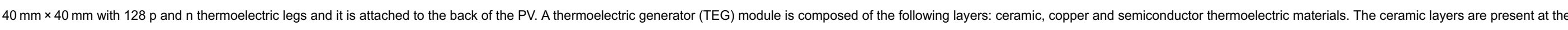

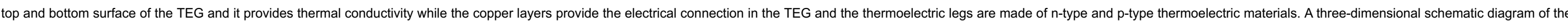

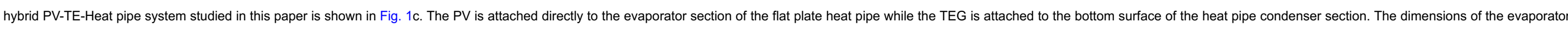
(C2019, Elsevier. This manuscript version is made available under the CC-BY-NC-ND 4.0 license http://creativecommons.org/licenses/by-nc-nd/4.0/ 


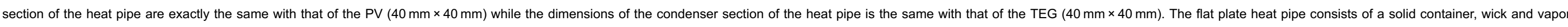
chamber as shown in Fig. 1d. The geometric parameters used in this study are listed in Table 1.
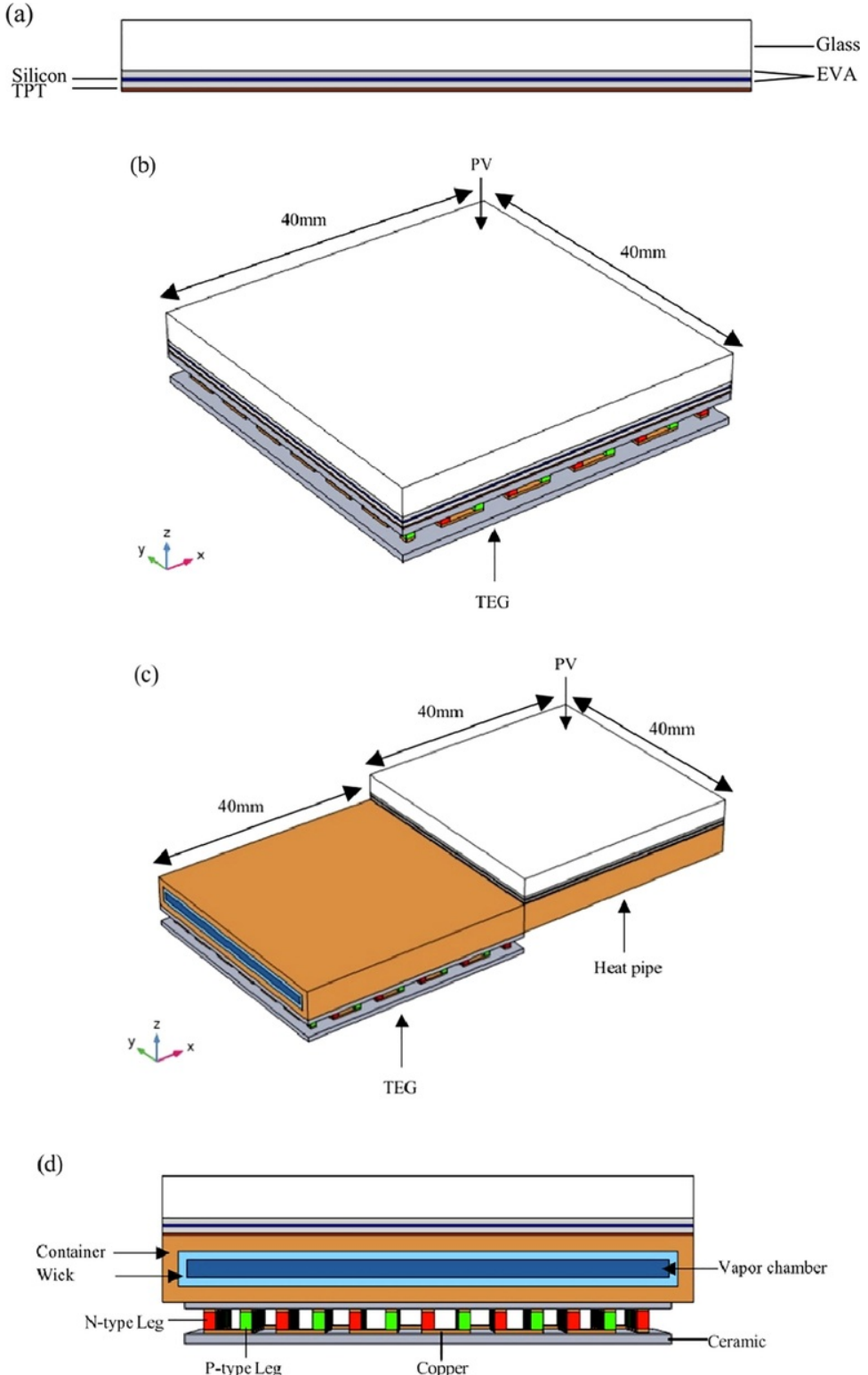

Fig. 1 Schematic diagram of (a) PV front view (b) three dimensional PV-TE (c) three dimensional PV-TE-Heat pipe (d) PV-TE-Heat pipe side view.

Table 1 Geometric parameters used in simulation $[34,43]$ 


\subsection{System operation description}

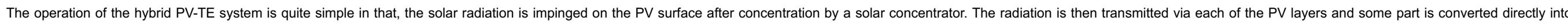

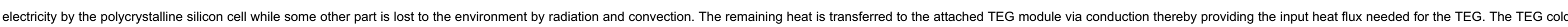

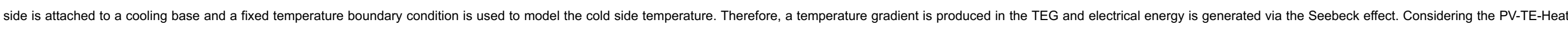

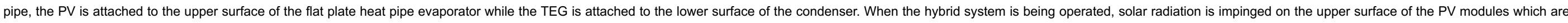

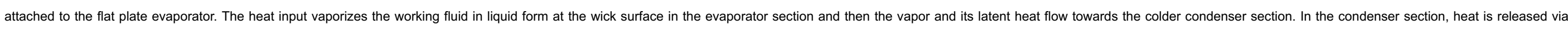

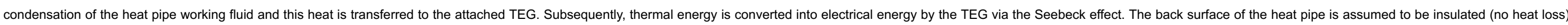
so as to create enough temperature difference across the attached thermoelectric generator.

\subsection{Material properties}

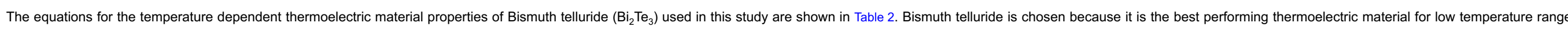

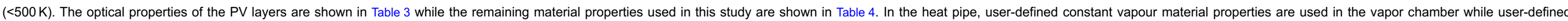
constant water material properties are used in the wick and copper material is used for the solid container.

Table 2 Temperature dependent thermoelectric material properties ( $\mathrm{T}$ is temperature in $\mathrm{K}$ ) [44] 
Seebeck coefficient, $\mathrm{S}[\mathrm{V} / \mathrm{K}]$

Thermal conductivity, $\mathrm{k}[\mathrm{W} /(\mathrm{m} \cdot \mathrm{K})]$

Table 3 Optical properties of PV materials [34].

\begin{tabular}{|c|c|c|c|c|}
\hline Material & Reflectivity & Absorptivity & Transmissivity & Emissivity \\
\hline Glass & $4.00 \times 10^{-2}$ & $4.00 \times 10^{-2}$ & $9.20 \times 10^{-1}$ & $8.50 \times 10^{-1}$ \\
\hline EVA & $2.00 \times 10^{-2}$ & $8.00 \times 10^{-2}$ & $9.00 \times 10^{-1}$ & \\
\hline Polycrystalline silicon & $8.00 \times 10^{-2}$ & $9.00 \times 10^{-1}$ & $2.00 \times 10^{-2}$ & \\
\hline TPT & $8.60 \times 10^{-1}$ & $1.28 \times 10^{-1}$ & $1.20 \times 10^{-2}-$ & $9.20 \times 10^{-1}$ \\
\hline
\end{tabular}

Table 4 Remaining material properties used for simulation $[28,34,41]$.

\begin{tabular}{|c|c|c|c|c|c|c|}
\hline & Heat capacity, $\quad c_{p}[\mathrm{~J} /(\mathrm{kgK})]$ & Density, $\rho^{\left[\mathrm{kg} / \mathrm{m}_{3}\right]}$ & Seebeck coefficient, $s[\mathrm{~V} / \mathrm{K}]$ & Electrical conductivity, $\sigma[\mathrm{S} / \mathrm{m}]$ & Thermal conductivity, $k[\mathrm{~W} /(\mathrm{mK})]$ & Dynamic viscosity, mu [Pa·s] \\
\hline Glass & $5 \times 10^{2}$ & $2.45 \times 10^{3}$ & - & - & 2.00 & - \\
\hline EVA & $2.09 \times 10^{3}$ & $9.60 \times 10^{2}$ & - & - & $3.11 \times 10^{-1}$ & - \\
\hline Silicon & $2.09 \times 10^{3}$ & $2.33 \times 10^{3}$ & - & - & $1.30 \times 10^{2}$ & - \\
\hline TPT & $1.25 \times 10^{3}$ & $1.20 \times 10^{3}$ & - & - & $1.50 \times 10^{-1}$ & - \\
\hline Vapor & 1874 & Idealgas $\rho_{v}=\frac{\mathrm{p}}{R_{s} \mathrm{~T}}$ & - & - & 0.0188 & $8.9 \times 10^{-6}$ \\
\hline Water & 4180 & 1000 & - & - & 0.61 & - \\
\hline Alumina & 900 & 3900 & - & - & 27 & - \\
\hline $\mathrm{Bi}_{2} \mathrm{Te}_{3}(\mathrm{p}-\mathrm{n}$ types$)$ & 154 & 7700 & $\pm S(T)$ Table 1 & $\sigma(T)$ Table 1 & $k(T)$ Table 1 & - \\
\hline Copper & 385 & 8960 & - & $58,100,000$ & 400 & - \\
\hline
\end{tabular}

\section{Numerical model}

The models used to describe the operation of the PV, TEG, Flat plate heat pipe and hybrid PV-TE are described in this section. Each of the subsystems are modelled individually firstly before being integrated into the hybrid system.

\subsection{Photovoltaic model}

The governing equations for the temperature distribution in each layer of the PV are given as [30]:

$\rho C_{p} \frac{\partial T}{\partial t}-\nabla \cdot(\mathrm{k} \nabla \mathrm{T})=\dot{\mathrm{q}}_{s o l}-\dot{\mathrm{P}}_{g e n}$

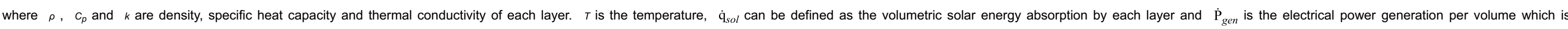
zero for all layers except the polycrystalline silicon cell layer.

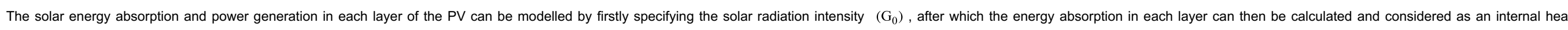
generation. In this study, the cell surface is assumed to always be uniformly illuminated. The volumetric energy absorption of each layer is given as:

(2019, Elsevier. This manuscript version is made available under the CC-BY-NC-ND 4.0 license http://creativecommons.org/licenses/by-nc-nd/4.0/ 


$$
\begin{aligned}
\dot{\mathrm{q}}_{s o l, \mathrm{i}} & =\frac{\mathrm{G}_{r e c, \mathrm{i}} \times \alpha_{i} \times A_{i} \times \mathrm{C}}{V_{i}} \\
\mathrm{G}_{r e c, \mathrm{i}} & =\mathrm{G}_{r e c, \mathrm{i}-1} \times\left[\left(1-\alpha_{\mathrm{i}-1}\right)-\rho_{\mathrm{i}-1}\right]
\end{aligned}
$$

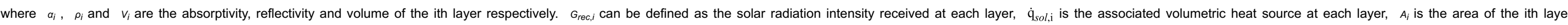
and $c$ is solar concentration ratio.

In the polycrystalline silicon layer, power generation is considered as an internal heat sink and can be defined as [33]:

$$
\eta_{p v}=\eta_{r e f}\left[1-\beta\left(T_{c}-\mathrm{T}_{r e f}\right)\right]
$$$$
\dot{\mathrm{P}}_{g e n}=\dot{\mathrm{q}}_{s o l, s i} \times \eta_{p v}
$$

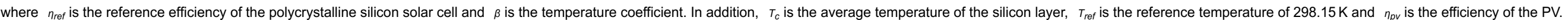

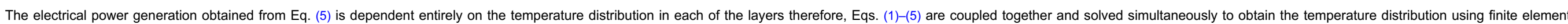
method.

\subsubsection{Boundary conditions}

To accurately model the PV, the following boundary conditions are applied, and some assumptions are considered to simplify the model with minimal deviation from the real case.

a) Solar cell conversion efficiency at $298.15 \mathrm{~K}$ is assumed to be $17 \%$ and temperature coefficient to be $0.0045 \mathrm{~K}^{-1}[34]$.

b) Steady state conditions are assumed.

c) All layers are assumed to be of equal area and in direct contact.

d) Heat loss via convection and radiation are considered at the upper surface (glass) and back surface (tedlar) of the PV.

e) Thermal properties of all materials are assumed to be isotropic and constant.

f) Ambient temperature is equal on all sides of the PV and adiabatic condition is assumed.

g) Convective heat transfer at the back surface of the PV is assumed to be half of that of the front surface [35].

h) In terms of radiative heat loss, the front and back surface of the PV are taken to view the sky and ground respectively.

The sky temperature used for the radiative heat loss calculation at the surface of the PV is given as [34]:

$\mathrm{T}_{s k y}=T_{a}-6(\mathrm{~K})$

where $T_{\text {sky }}$ is sky temperature and $T_{a}$ is ambient temperature.

The convective heat transfer coefficient of the PV is given in terms of the wind speed as [36] $\mathrm{h}=5.82+4.07 \mathrm{v}$

where $h$ is the convective heat transfer coefficient $v$ is the wind speed $(\mathrm{m} / \mathrm{s})$

\subsection{Thermoelectric generator model}

The governing equations for the TEG which are solved by using COMSOL 5.4 Multiphysics software are given as [37]:

$\rho C_{p} \frac{\partial T}{\partial t}+\nabla \cdot \overrightarrow{\mathrm{q}}=\dot{\mathrm{q}}$

where $\rho$ is the density, $C_{p}$ is specific heat capacity, $T$ is temperature, $\vec{q}$ is heat flux vector and $\dot{q}$ is the heat generation rate per unit volume.

(C2019, Elsevier. This manuscript version is made available under the CC-BY-NC-ND 4.0 license http://creativecommons.org/licenses/by-nc-nd/4.0/ 
$\nabla \cdot\left(\overrightarrow{\mathrm{J}}+\frac{\partial \overrightarrow{\mathrm{D}}}{\partial t}\right)=0$

where $\vec{J}$ is the electric current density vector and $\vec{D}$ is the electric flux density vector.

Eqs. (5) and (6) are coupled using the following thermoelectric constitutive equations [39],

$\overrightarrow{\mathrm{q}}=\mathrm{T}[\alpha] \cdot \overrightarrow{\mathrm{J}}-[\kappa] \cdot \nabla \mathrm{T}$

$\overrightarrow{\mathrm{J}}=[\sigma] \cdot(\overrightarrow{\mathrm{E}}-[\alpha] \cdot \nabla \mathrm{T})$

where $[a]$ is the Seebeck coefficient matrix, $[k]$ is the thermal conductivity matrix and $[\sigma]$ represents the electrical conductivity matrix.

$\overrightarrow{\mathrm{E}}=-\nabla \varphi$

where $\overrightarrow{\mathrm{E}}$ represents the electric field intensity vector and $\varphi$ is the electric scalar potential.

The coupled thermoelectric equations can be obtained by combining the above equations as,

$$
\begin{aligned}
& \rho_{d} C_{p} \frac{\partial T}{\partial t}+\nabla \cdot(\mathrm{T}[\alpha] \cdot \overrightarrow{\mathrm{J}})-\nabla \cdot([\alpha] \cdot \nabla \mathrm{T})=\dot{\mathrm{q}} \\
& \nabla \cdot\left([\varepsilon] \cdot \nabla \frac{\partial \varphi}{\partial t}\right)+\nabla \cdot([\sigma] \cdot[\alpha] \cdot \nabla \mathrm{T})+\nabla \cdot([\sigma] \cdot \nabla \varphi)=0
\end{aligned}
$$

where $[\varepsilon]$ represents the dielectric permittivity matrix.

Lastly, the coupled thermoelectric governing equations can rewritten as [40],

$\nabla \cdot(T \alpha \overrightarrow{\mathrm{J}})-\nabla \cdot(\lambda \nabla \mathrm{T})=\dot{\mathrm{q}}$

$\nabla \cdot(\sigma \alpha \nabla \mathrm{T})+\nabla \cdot(\sigma \nabla \varphi)=0$

The electrical performance of the TEG can be obtained from the following equations [8]:

$\mathrm{V}_{O C}=\alpha \Delta \mathrm{T}$

where $V_{O C}$ is the open circuit voltage, $a$ is the Seebeck coefficient and $\Delta T=T_{h}-T_{C}$ is the temperature difference between the hot side and cold side of the thermoelectric generator.

$V_{L}=\mathrm{V}_{O C}-\mathrm{R}_{i n} \mathrm{I}=R_{L} \mathrm{I}$

Wwhere $v_{L}$ is the output load voltage, $R_{\text {in }}$ is the internal resistance of the TEG and $I$ is the TEG current which is given as,

$\mathrm{I}=\frac{\mathrm{V}_{O C}}{\mathrm{R}_{\text {in }}+R_{L}}=\frac{\alpha \Delta \mathrm{T}}{\mathrm{R}_{\text {in }}+R_{L}}$

The output power of the TEG $\left(P_{\text {teg }}\right.$ is given as,

$\mathrm{P}_{\text {teg }}=V_{L} \mathrm{I}=R_{L} \mathrm{I}^{2}=\frac{R_{L} \cdot \alpha^{2} \cdot \Delta \mathrm{T}^{2}}{\left(\mathrm{R}_{\text {in }}+R_{L}\right)^{2}}$

$\eta_{\text {teg }}=\mathrm{P}_{\text {teg }} \times Q_{h}$

where $\eta_{\text {teg }}$ is the TEG efficiency and $Q_{h}$ is the input heat flux at the top surface of the TEG.

\subsubsection{Boundary conditions}

a) Heat loss through convection and radiation on all surfaces of the TEG are assumed to be zero.

b) Electrical and thermal contact resistances are ignored.
\[ 2019 \text {, Elsevier. This manuscript version is made available under the CC-BY-NC-ND } 4.0 \text { license http://creativecommons.org/licenses/by-nc-nd/4.0/ } \] 
d) The copper on the $n$-type thermoelectric leg is assumed to be at zero potential while the one at the p-type leg is connected to the external load resistance circuit.

\subsection{Flat plate heat pipe model}

The flat plate heat pipe model used in this study is a simplified model given by [41] and modified for this particular study.

The capillary pressure is given as:

$\Delta p_{c}=\frac{2 \sigma}{r_{c}}$

where $r_{c}$ is the capillary radius and $\sigma$ is the surface tension

The capillary pressure must be greater than all other pressure drops in the heat pipe therefore, $\Delta p_{c} \geq \Delta p_{v}+\Delta p_{l}+\Delta p_{g}$

where $\Delta p_{v}$ is the vapor pressure drop, $\Delta p_{c}$ is capillary pressure drop, $\Delta p_{l}$ is liquid pressure drop in wick and $\Delta p_{g}$ is pressure drop due to gravitation and acceleration.

$\Delta p_{l}=\left(\frac{\mu_{l}}{\mathrm{~K} A_{w} L_{v} p_{l}}\right) \mathrm{L}_{e f f} \mathrm{q}$

where $\mu_{l}$ is the liquid viscosity, $K$ is wick permeability, $A_{w}$ is wick area, $L_{\text {eff }}$ is the heat pipe effective length and $q$ is the capillary limit.

The vapor pressure drop $\Delta p_{v}$ can often be neglected and if the effect of gravity is not considered then,

$\Delta p_{c}=\Delta p_{l}$

The capillary limit is given as:

$\mathrm{q}=\frac{2 \sigma K A_{w} L_{v} p_{l}}{\mathrm{~L}_{\text {eff }} r_{c} \mu_{l}}$

$\mathrm{L}_{\text {eff }}=\frac{\mathrm{L}_{\text {evap }}}{2}+\frac{\mathrm{L}_{\text {conden }}}{2}$

where $L_{\text {evap }}$ is the length of evaporator section and $L_{\text {conden }}$ is the length of condenser section of the heat pipe.

The effective thermal conductivity of the sintered copper powder wick is given as [41]:

$\mathrm{k}_{\text {eff }}=\frac{k_{f}\left(k_{f}+k_{s}-(1-\varphi)\left(k_{f}-k_{s}\right)\right)}{k_{f}+k_{s}+(1-\varphi)\left(k_{f}-k_{s}\right)}$

where $\varphi$ is porosity, taken as $0.5, k_{f}$ and $k_{s}$ are thermal conductivity of fluid (water) and thermal conductivity of solid (copper) respectively, taken as 0.61 and 400 respectively.

The vapor density according to the Ideal gas law is given as:

$$
\rho_{v}=\frac{\mathrm{p}}{R_{s} \mathrm{~T}}=\frac{\mathrm{p} \times M_{n}}{R_{s} \mathrm{~T}}
$$

where $p$ is pressure and $M_{n}$ is the molar mass $(18.01528[\mathrm{~g} / \mathrm{mol}])$

Laminar compressible flow is used and the saturation pressure (from Clausius-Clapeyron) at the inlet/outlet at evaporator/condenser side of the wick/vapor interface is given as:

$\mathrm{p}=\mathrm{p}_{\text {sat }}(\mathrm{T})=\mathrm{p}_{\text {ref }} \bullet \exp \left(\frac{\lambda}{R_{s}}\left(\frac{1}{\mathrm{~T}_{\text {ref }}}-\frac{1}{\mathrm{~T}}\right)\right)$ 


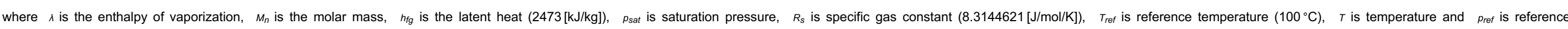
pressure (1 atm).

A global analytical function is used to define the saturation pressure and the vapor density is calculated from the equation.

The resulting normal mass flux of the evaporating/condensing water at the wick/vapor interface is given as, $\dot{\mathrm{m}}=\rho_{\nu}(\mathrm{v} \cdot \mathrm{n})$

where $\rho_{v}$ is vapor density, $v$ is velocity field component and $n$ is normal direction.

Viscous dissipation is included in this model and heat conduction is present in the container and wick. In the vapor chamber, heat transfer is via conduction and convection.

The boundary heat source that accounts for the heat of evaporation/condensation at the wick/vapor interface is given as:

$\mathrm{q}_{\text {evap }}=\dot{\mathrm{m}} \lambda$

where $\dot{m}$ is normal mass flux and $\lambda$ is the enthalpy of vaporization.

A global variable is used to define the heat of vaporization $q_{\text {evap }}$ and a boundary heat source is used to apply it to the wick/vapor interface.

\subsubsection{Boundary conditions}

To accurately model the flat plate heat pipe, the following boundary conditions are applied, and some assumptions are considered to simplify the model [41]

a) Effect of gravity is neglected.

b) Heat transfer is mainly due to evaporation/condensation and convection of vapor. Therefore, heat transport in the wick is simplified as conduction with an effective heat transfer coefficient.

c) Constant material properties are used except for that of the vapor density

d) This simplified model does not predict the operating limits of the heat pipe.

e) Convective heat transfer coefficient used at the top surface of the heat pipe is assumed to be $1200 \mathrm{~W} / \mathrm{m}^{2} / \mathrm{K}$.

f) Sintered copper powder wick is used with porosity $\varphi=0.5$

\subsection{Hybrid model}

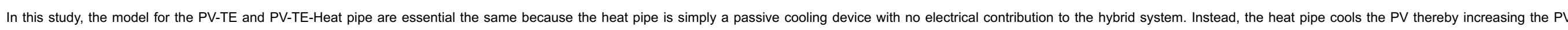
efficiency while also providing some heat flux at its condenser section for the TEG to generate electricity simultaneously.

The total power output of the hybrid system is a sum of the polycrystalline silicon cell layer power output and the TEG power output at matched load resistance. This is given as:

$\mathrm{P}_{\text {total }}=\dot{\mathrm{P}}_{\text {gen }}+\mathrm{P}_{\text {teg }}$

Similarly, the overall efficiency of the hybrid system is given as the sum of the PV and TEG efficiencies.

$\eta_{\text {total }}=\eta_{p v}+\eta_{\text {teg }}$

\subsection{Computational domain}

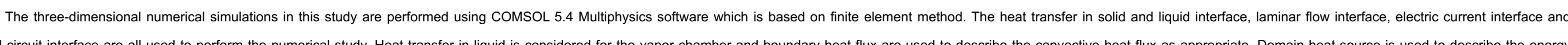

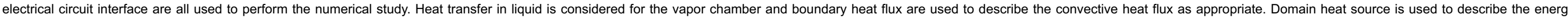

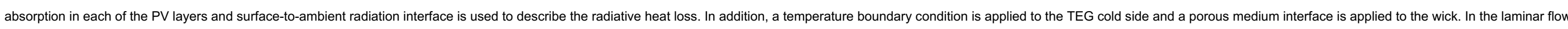

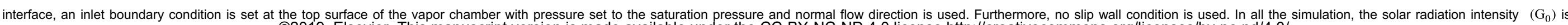
O2019. Elsevier. This manuscript version is made available under the CC-BY-NC-ND 4.0 license http://creativecommons.org/licenses/by-nc-nd/4.0/ 


\subsection{Model validation}

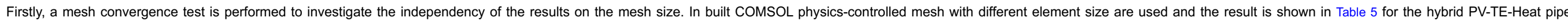

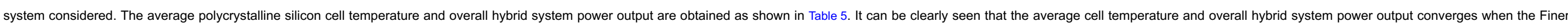
mesh is used. Therefore, for increased accuracy and to save computation time, the Finer mesh is used in all the simulations.

\section{Table 5 Mesh convergence test.}

\begin{tabular}{|c|c|c|c|}
\hline Number of domain elements & Element size & Average cell temperature $(\mathrm{K})$ & Overall hybrid power output (W) \\
\hline 70,269 & Coarse & 310.72 & 0.798606514 \\
\hline 148,342 & Normal & 310.72 & 0.798597914 \\
\hline 328,627 & Fine & 310.72 & 0.798587814 \\
\hline $1,205,452$ & Finer & 310.71 & 0.798598067 \\
\hline $3,547,403$ & Extra fine & 310.71 & 0.798598067 \\
\hline
\end{tabular}

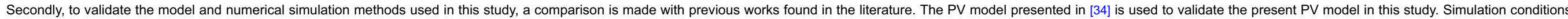

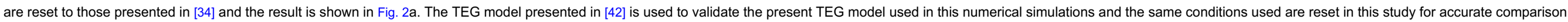



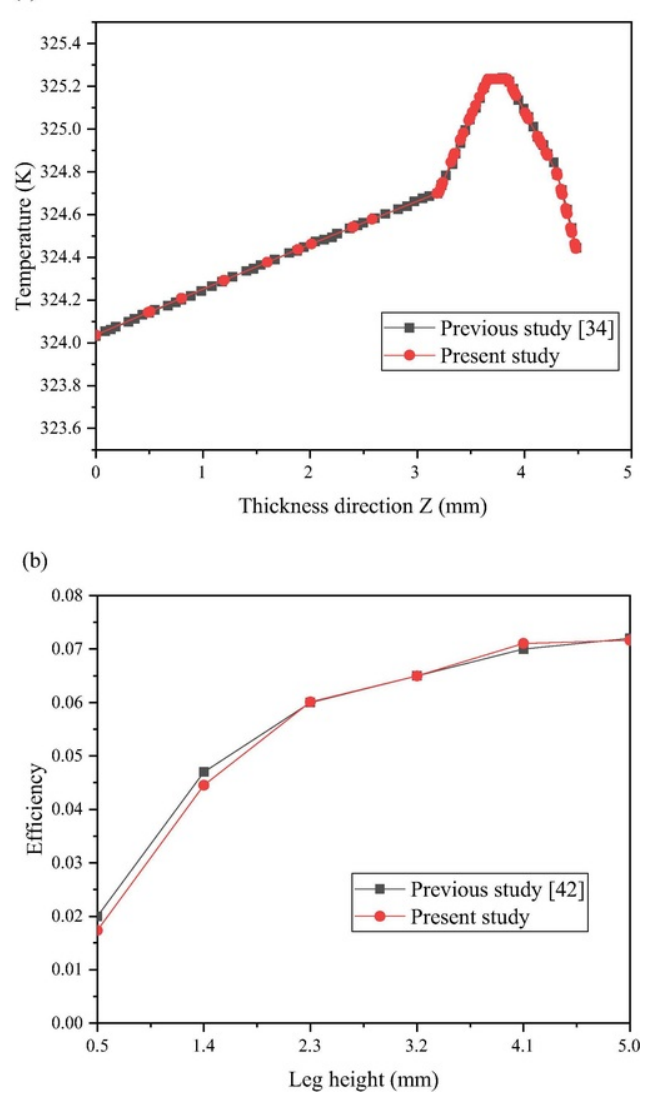

Fig. 2 Validation of (a) PV model with [34] and (b) TEG model with [42].

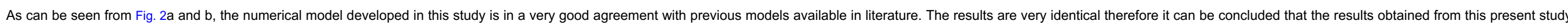

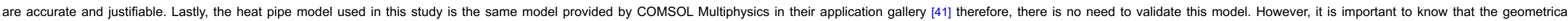
dimensions have been modified for the sake of this present study.

\section{Results and discussion}

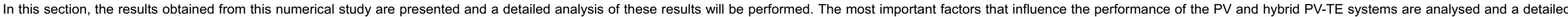
comparison between the performance of the PV only, PV-TE and PV-TE-Heat pipe under the influence of varying solar concentration ratio, ambient temperature, wind speed and TEG cold side temperature is presented.

\subsection{Influence of solar concentration ratio}

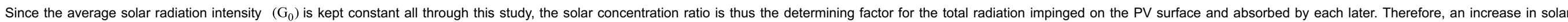

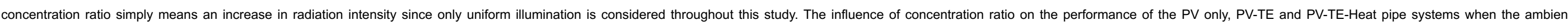

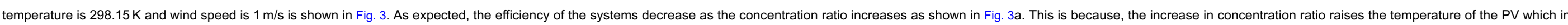

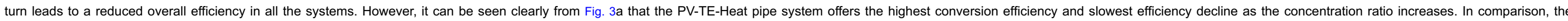

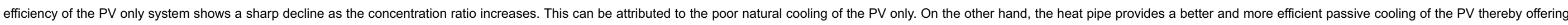
(C2019, Elsevier. This manuscript version is made available under the CC-BY-NC-ND 4.0 license http://creativecommons.org/licenses/by-nc-nd/4.0/ 


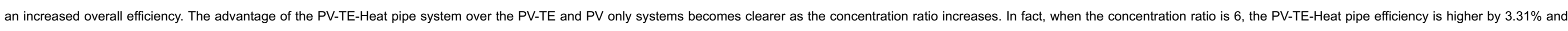

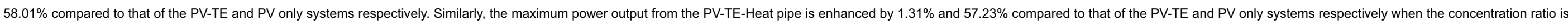

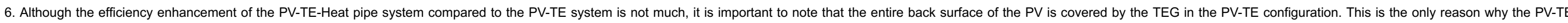

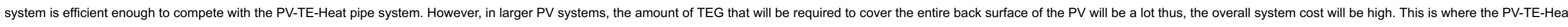

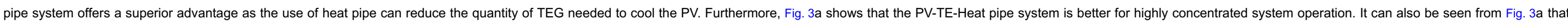

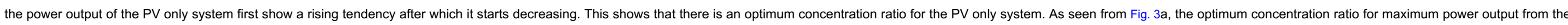

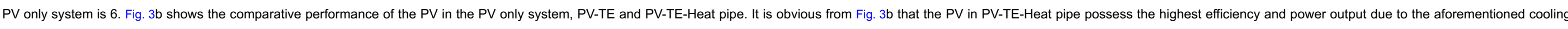

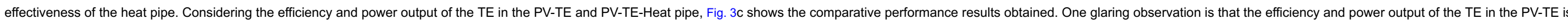

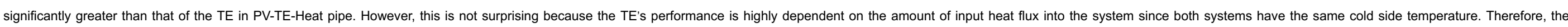

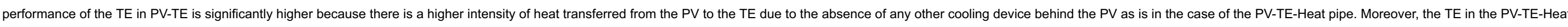

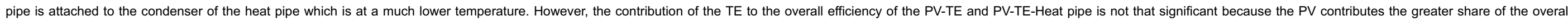
hybrid system efficiency. Consequently, the performance of the PV-TE-Heat pipe is still better than that of the PV-TE because the PV is better cooled. 

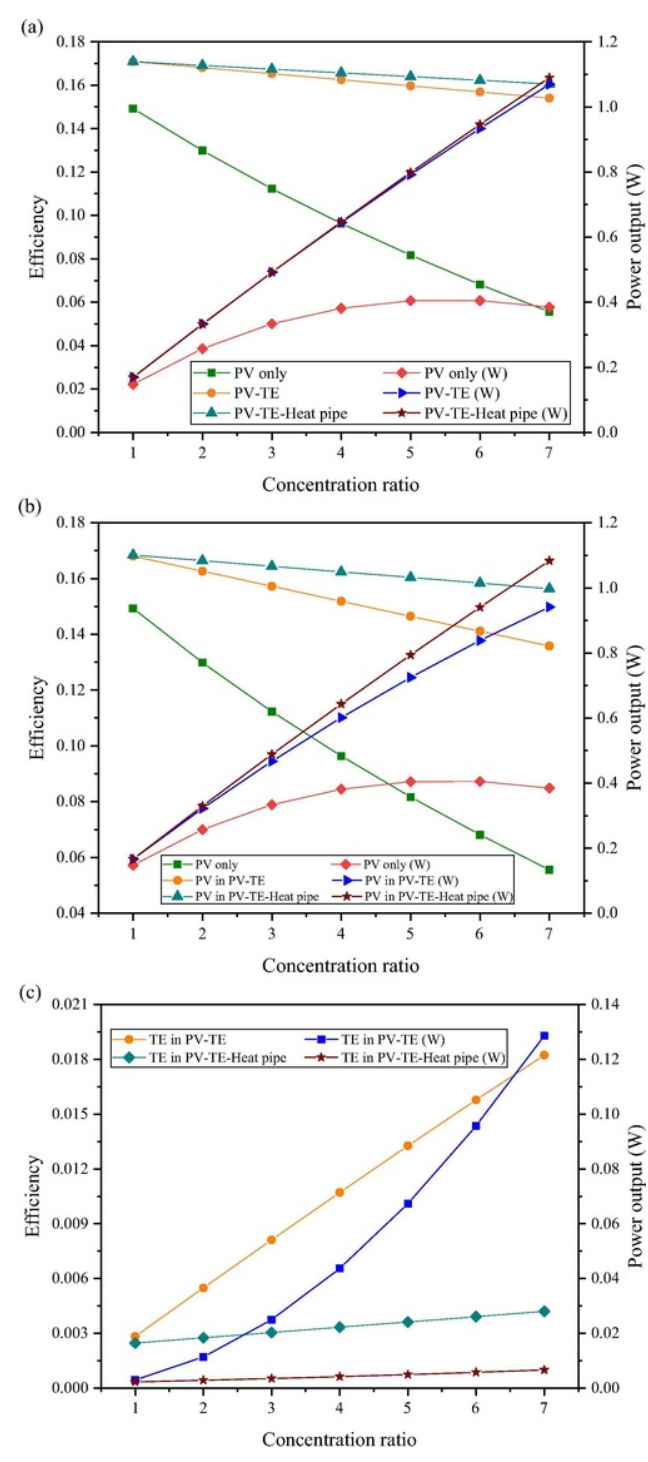

Fig. 3 Variation of concentration ratio with (a) overall (b) PV (c) TE efficiency and power output.

\subsection{Influence of ambient temperature}

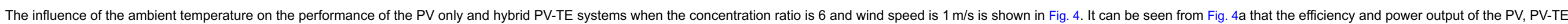

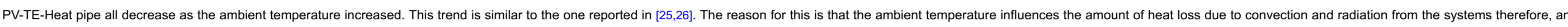

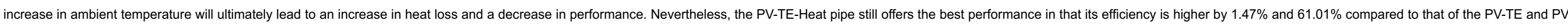

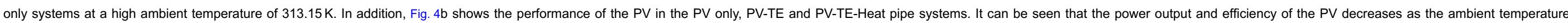

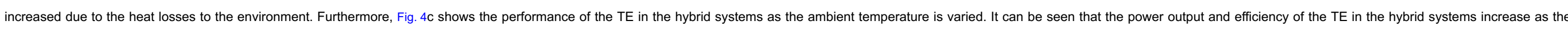

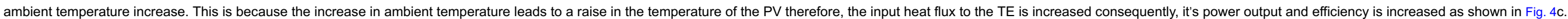



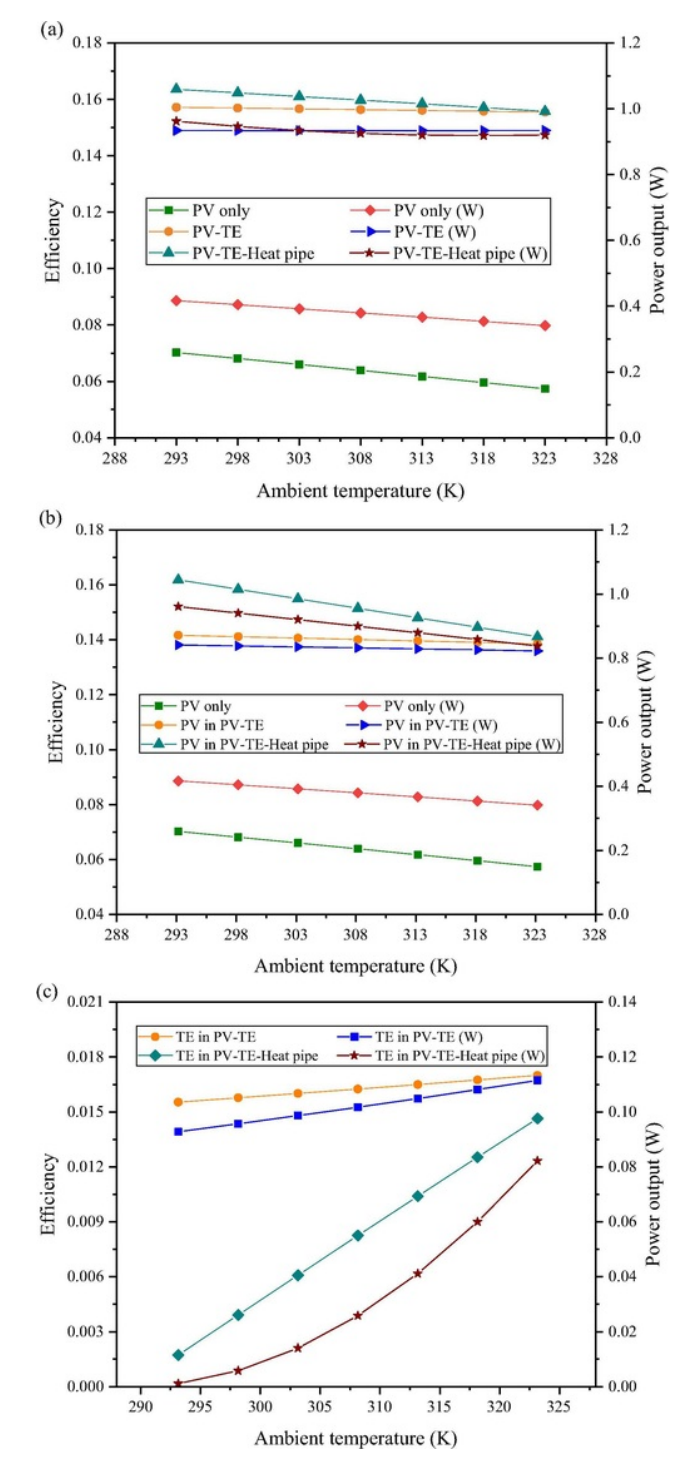

Fig. 4 Ambient temperature variation with (a) overall (b) PV (c) TE efficiency and power output.

\subsection{Influence of wind speed}

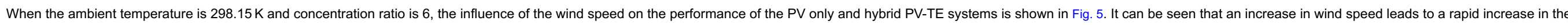

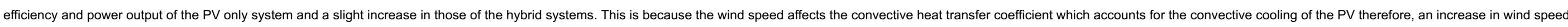

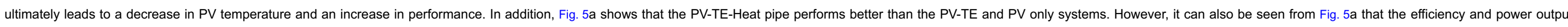

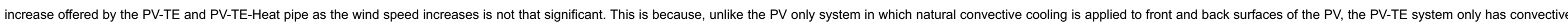

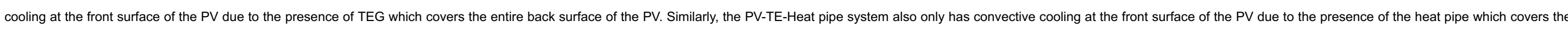

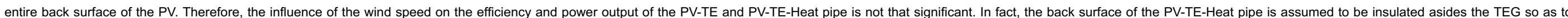
(C2019, Elsevier. This manuscript version is made available under the CC-BY-NC-ND 4.0 license http://creativecommons.org/licenses/by-nc-nd/4.0/ 

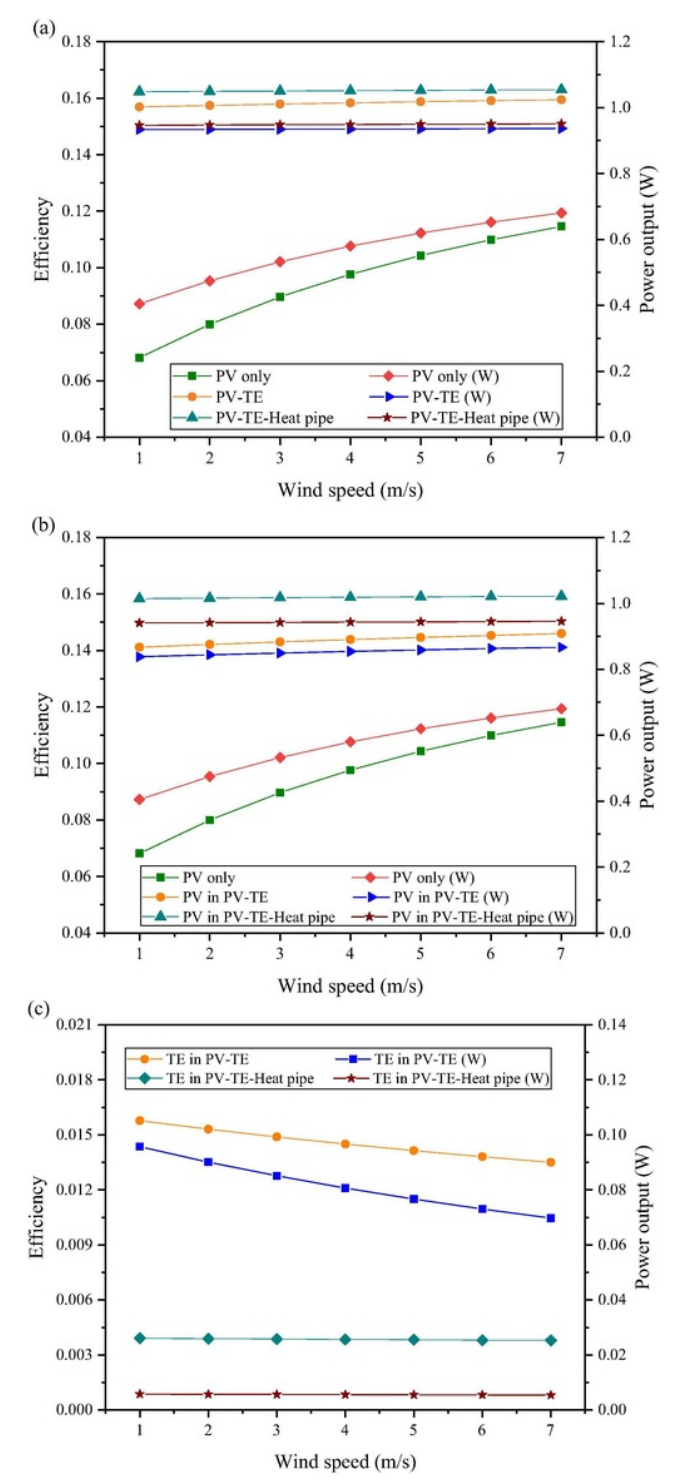

Fig. 5 Variation of wind speed with (a) overall (b) PV (c) TE efficiency and power output.

\subsection{Influence of thermoelectric generator cold side temperature}

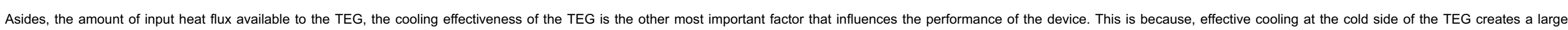

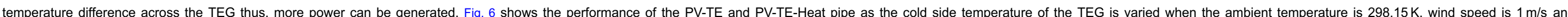
C2019, Elsevier. This manuscript version is made available under the CC-BY-NC-ND 4.0 license http://creativecommons.org/licenses/by-nc-nd/4.0/ 

increases thereby showing how highly important effective cooling of TEG is

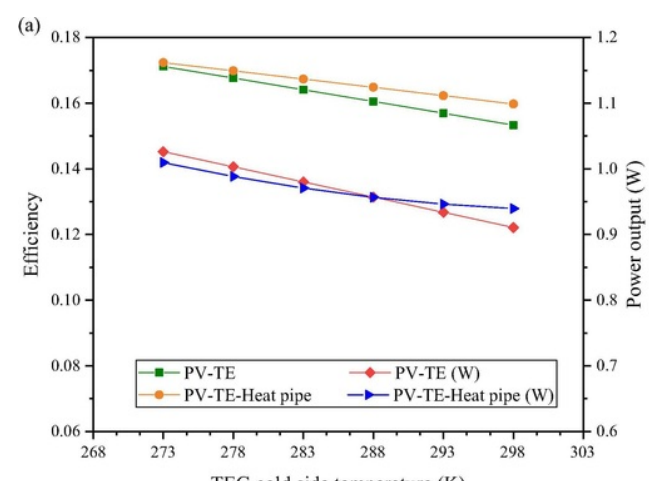

TEG cold side temperature $(\mathrm{K})$
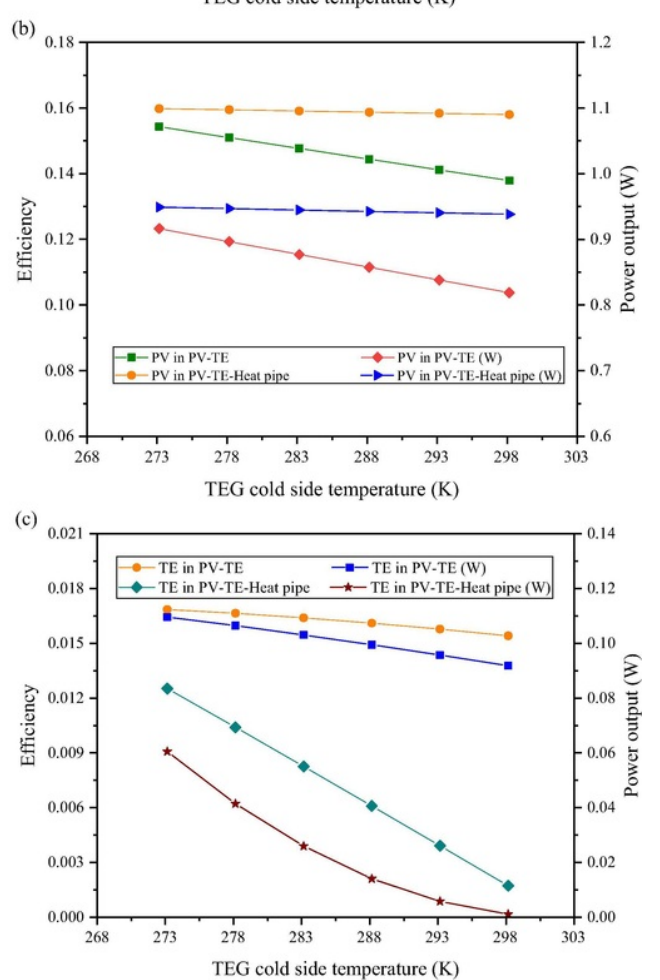

Fig. 6 TEG cold side temperature variation with (a) overall (b) PV (c) TE efficiency and power output.

\subsection{Temperature and voltage distribution}

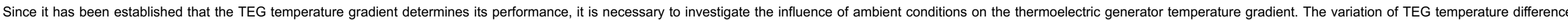
02019, Elsevier. This manuscript version is made available under the CC-BY-NC-ND 4.0 license http://creativecommons.org/licenses/by-nc-nd/4.0/ 


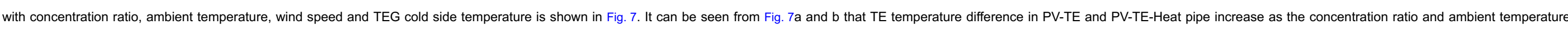

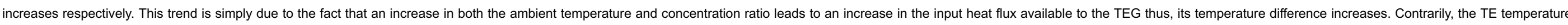

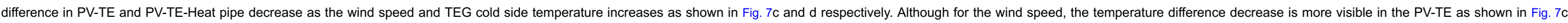

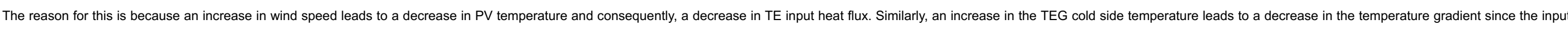
heat flux is still constant.
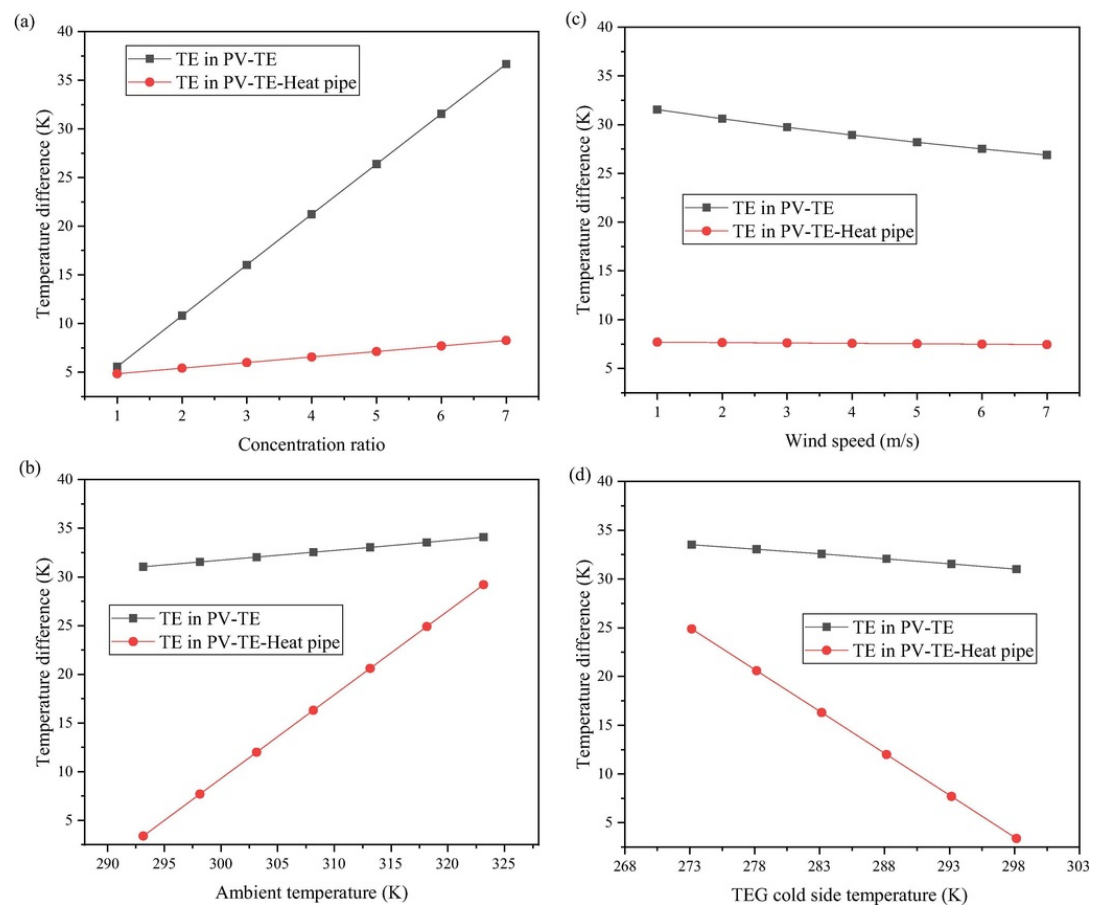

Fig. 7 Variation of TEG temperature difference with (a) concentration ratio (b) ambient temperature (c) wind speed (d) TEG cold side temperature.

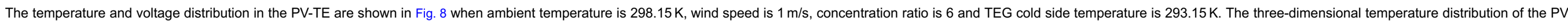

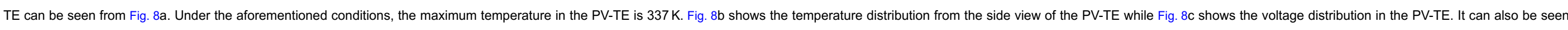
that the highest temperature in the hybrid PV-TE system is generated at the polycrystalline silicon layer. 
(a)

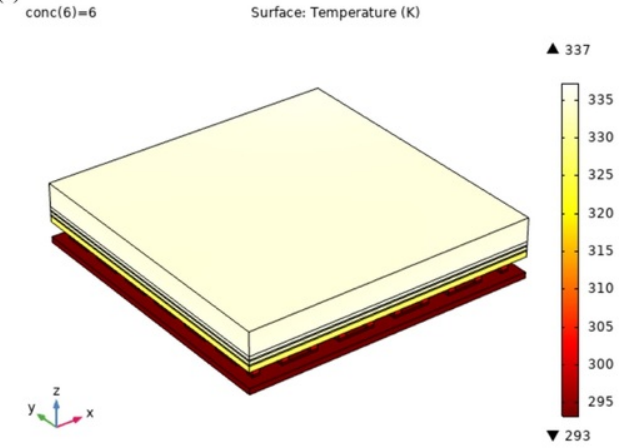

(b) Surface: Temperature (K)

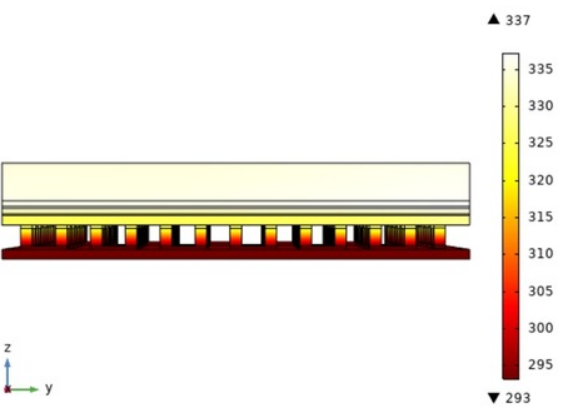

(c)

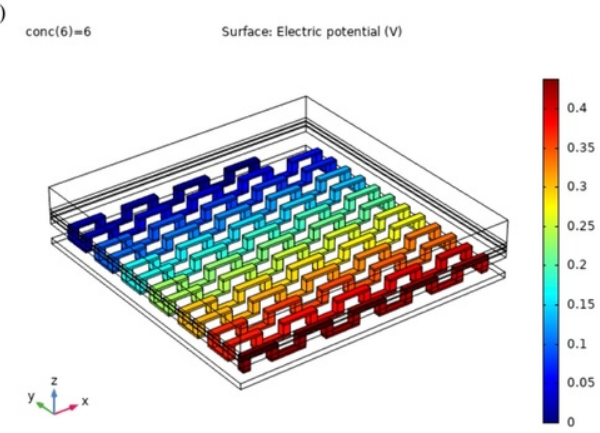

Fig. 8 PV-TE temperature distribution in (a) three-dimension (b) side view (c) voltage distribution.

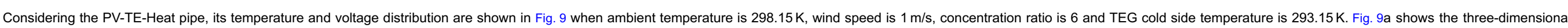

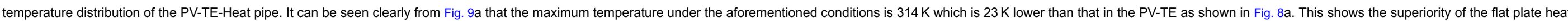

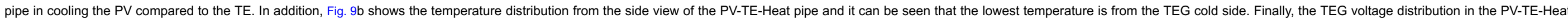
pipe is shown in Fig. 9c. The thermoelectric legs are connected in series therefore, current flows across all the legs and voltage can be measure across the negative and positive terminals. 
(a)

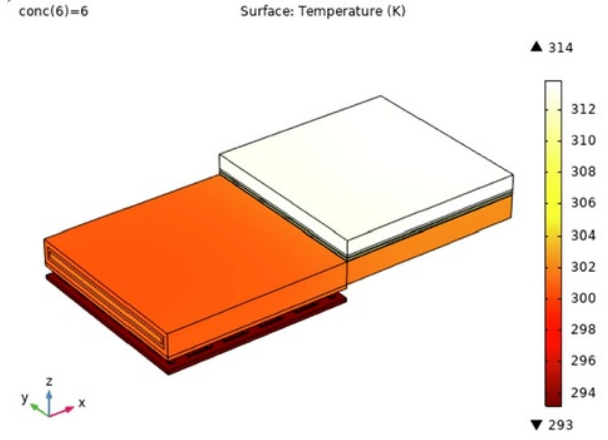

(b)

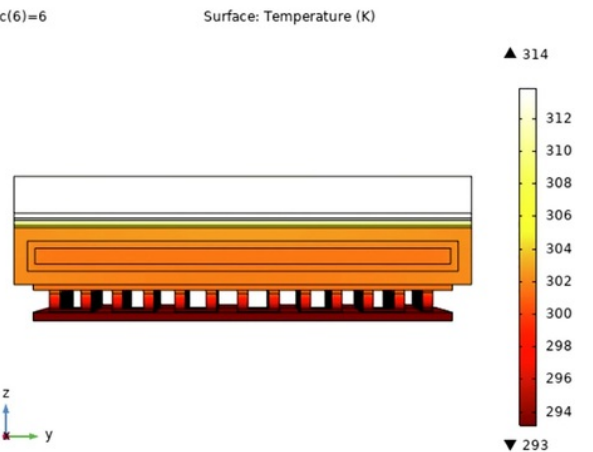

(c)

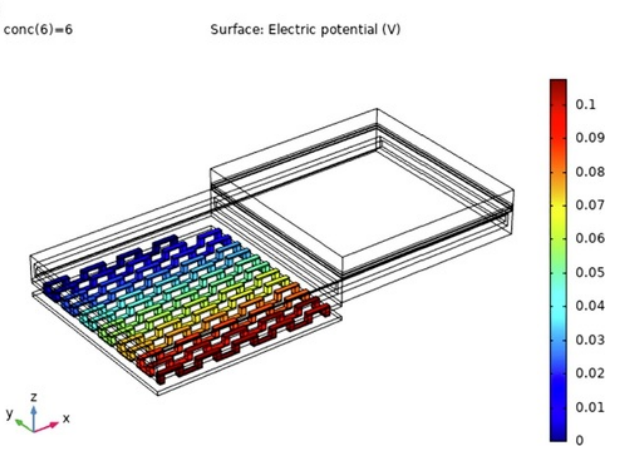

Fig. 9 PV-TE-Heat pipe temperature distribution in (a) three-dimension (b) side view (c) voltage distribution.

\section{Conclusion}

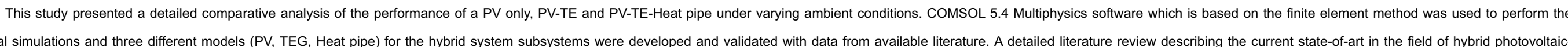

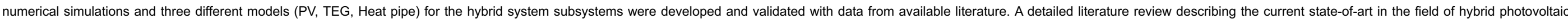

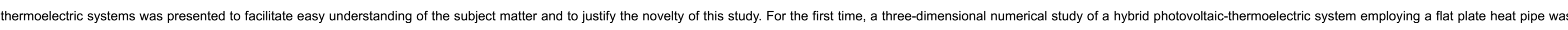
presented. Temperature dependent thermoelectric material properties were also accounted to increase the accuracy of the simulation results. The main conclusions from this study are as follows:

1) The PV-TE-Heat pipe system is recommended for highly concentrated systems because of its superior performance at high concentration ratios.

(C2019, Elsevier. This manuscript version is made available under the CC-BY-NC-ND 4.0 license http://creativecommons.org/licenses/by-nc-nd/4.0/ 
2) Efficiency of the PV-TE-Heat pipe is $3.31 \%$ and $58.01 \%$ higher compared to that of the PV-TE and PV only systems respectively at a concentration ratio of 6 .

3) There exists an optimum concentration ratio for the maximum power output from the PV only system and it is 6 .

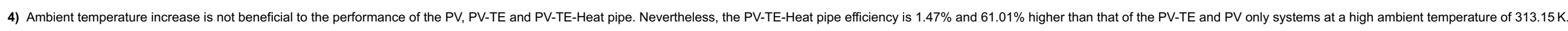

5) Increase in wind speed enhances the performance of the PV, PV-TE and PV-TE-Heat pipe although the enhancement is not significant in the PV-TE and PV-TE-Heat pipe.

6) Although the PV-TE-Heat pipe system is recommended because of its superior performance, it is worth noting that the PV-TE system is also a better alternative to the PV only system because its performance is better compared to the PV only system.

7) The PV and TE have a complex relationship in that some ambient conditions are beneficial to the performance of the PV while harming that of the TEG and vice versa.

8) Ineffective cooling of the TEG could cause a negative effect on the performance of the hybrid systems.

\section{Declaration of interests}

The authors declare that they have no known competing financial interests or personal relationships that could have appeared to influence the work reported in this paper.

\section{Acknowledgements}

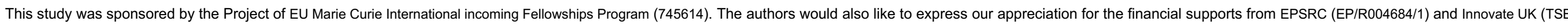

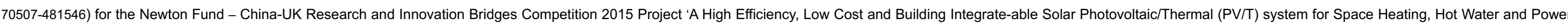
Supply' and DongGuan Innovation Research Team Program (No. 2014607101008).

\section{References}

[1] M. Fisac, F.X. Villasevil and A.M. López, High-efficiency photovoltaic technology including thermoelectric generation, J Power Sources 252, 2014, 264-269, https://doi.org/10.1016/j.jpowsour.2013.11.121.

[2] G. Li, S. Shittu, T.M.O. Diallo, M. Yu, X. Zhao and J. Ji, A review of solar photovoltaic-thermoelectric hybrid system for electricity generation, Energy 158, 2018, 41-58, https://doi.org/10.1016/j.energy.2018.06.021.

[3] P. Huen and W.A. Daoud, Advances in hybrid solar photovoltaic and thermoelectric generators, Renewable Sustainable Energy Rev 72, 2017, 1295-1302, https://doi.org/10.1016/j.rser.2016.10.042.

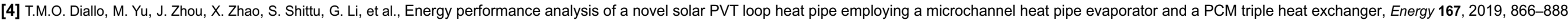
https://doi.org/10.1016/j.energy.2018.10.192.

[5] A. Makki, S. Omer and H. Sabir, Advancements in hybrid photovoltaic systems for enhanced solar cells performance, Renewable Sustainable Energy Rev 41, 2015, 658-684, https://doi.org/10.1016/j.rser.2014.08.069.

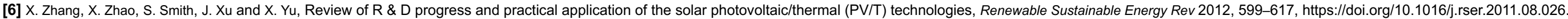

[7] M. Benghanem, A.A. Al-Mashraqi and K.O. Daffallah, Performance of solar cells using thermoelectric module in hot sites, Renewable Energy 89, 2016, 51-59, https://doi.org/10.1016/j.renene.2015.12.011.

[8] S. Shittu, G. Li, X. Zhao, X. Ma, Y.G. Akhlaghi and E. Ayodele, High performance and thermal stress analysis of a segmented annular thermoelectric generator, Energy Convers Manage 184, 2019, 180-193,

https://doi.org/10.1016/j.enconman.2019.01.064.

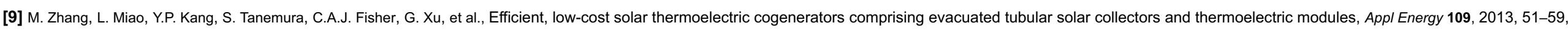
https://doi.org/10.1016/j.apenergy.2013.03.008.

[10] W. He, G. Zhang, X. Zhang, J. Ji, G. Li and X. Zhao, Recent development and application of thermoelectric generator and cooler, Appl Energy 143, 2015, 1-25, https://doi.org/10.1016/j.apenergy.2014.12.075.

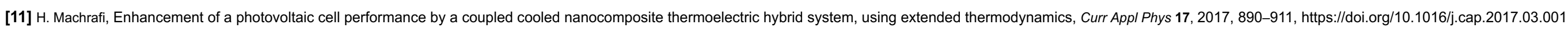

[12] H. Hashim, J.J. Bomphrey and G. Min, Model for geometry optimisation of thermoelectric devices in a hybrid PV/TE system, Renewable Energy 87, 2016, 458-463, https://doi.org/10.1016/j.renene.2015.10.029.

[13] F. Xin, T. Ma and Q. Wang, Thermal performance analysis of flat heat pipe with graded mini-grooves wick, Appl Energy 228, 2018, 2129-2139, https://doi.org/10.1016/j.apenergy.2018.07.053.

(02019, Elsevier. This manuscript version is made available under the CC-BY-NC-ND 4.0 license http://creativecommons.org/licenses/by-nc-nd/4.0/ 
[14] M.C. Zaghdoudi, S. Maalej, J. Mansouri and M.B.H. Sassi, Flat miniature heat pipes for electronics cooling: state of the art, experimental and theoretical analysis, Int J Eng App/ Sci 7, 2011 , 166-189.

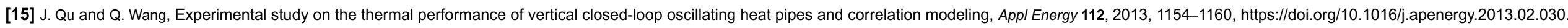

[16] H. Jouhara, A. Chauhan, T. Nannou, S. Almahmoud, B. Delpech and L.C. Wrobel, Heat pipe based systems - advances and applications, Energy 128, 2017, 729-754, https://doi.org/10.1016/j.energy.2017.04.028.

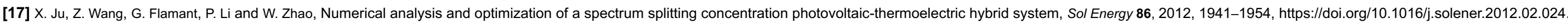

[18] E. Yin, Q. Li and Y. Xuan, A novel optimal design method for concentration spectrum splitting photovoltaic thermoelectric hybrid system, Energy 163, 2018, 519-532, https://doi.org/10.1016/j.apenergy.2018.05.127.

[19] W.G.J.H.M. Van Sark, Feasibility of photovoltaic - thermoelectric hybrid modules, Appl Energy 88, 2011, 2785-2790, https://doi.org/10.1016/j.apenergy.2011.02.008.

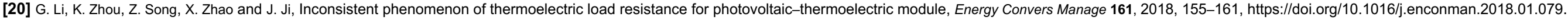

[21] J. Zhang and Y. Xuan, An integrated design of the photovoltaic-thermoelectric hybrid system, Sol Energy 177, 2019, 293-298, https://doi.org/10.1016/j.solener.2018.11.012.

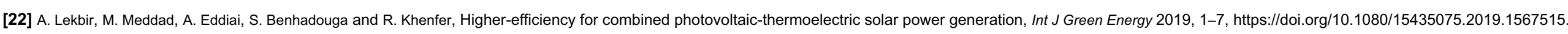

[23] P.M. Rodrigo, A. Valera, E.F. Fernández and F.M. Almonacid, Performance and economic limits of passively cooled hybrid thermoelectric generator-concentrator photovoltaic modules, Appl Energy 238, 2019, 1150-1162, https://doi.org/10.1016/J.APENERGY.2019.01.132.

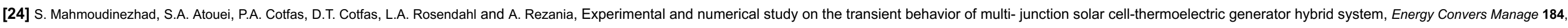
2019, 448-455, https://doi.org/10.1016/j.enconman.2019.01.081.

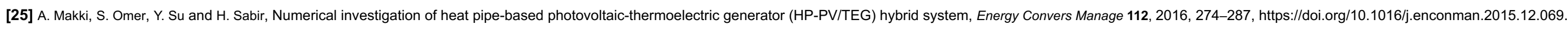

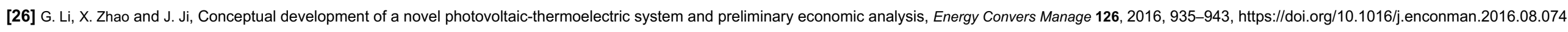

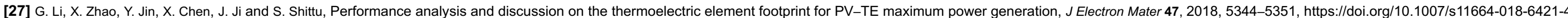

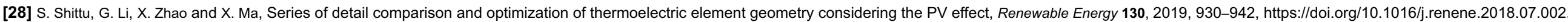

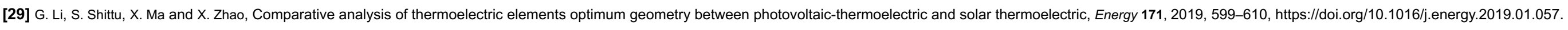

[30] H.R. Fallah Kohan, F. Lotfipour and M. Eslami, Numerical simulation of a photovoltaic thermoelectric hybrid power generation system, Sol Energy 174, 2018, 537-548, https://doi.org/10.1016/j.solener.2018.09.046.

[31] F. Meng, L. Chen and F. Sun, Effects of temperature dependence of thermoelectric properties on the power and efficiency of a multielement thermoelectric generator, Int J Energy Environ 3, 2012, 137-150.

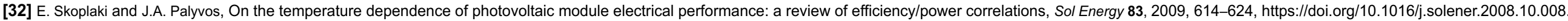

[33] D.L. Evans, Simplified method for predicting photovoltaic array output, Sol Energy 27, 1981, 555-560.

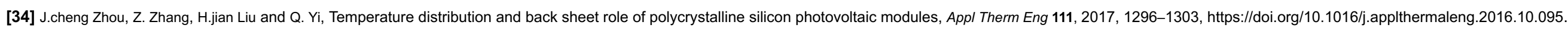

[35] Y. Lee and A.A.O. Tay, Finite element thermal analysis of a solar photovoltaic module, Energy Procedia 15, 2012, 413-420, https://doi.org/10.1016/j.egypro.2012.02.050.

[36] J. Zhou, Q. Yi, Y. Wang and Z. Ye, Temperature distribution of photovoltaic module based on finite element simulation, Sol Energy 111, 2015, 97-103, https://doi.org/10.1016/j.solener.2014.10.040.

[37] J. Xiao, T. Yang, P. Li, P. Zhai and Q. Zhang, Thermal design and management for performance optimization of solar thermoelectric generator, Appl Energy 93, 2012, 33-38, https://doi.org/10.1016/j.apenergy.2011.06.006.

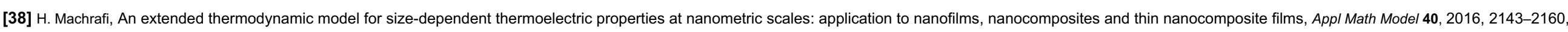
https://doi.org/10.1016/j.apm.2015.09.044.

[39] Antonova EE, Looman DC. Finite elements for thermoelectric device analysis in ANSYS. In: ICT 2005. 24th International Conf. Thermoelectr. 2005, p. 200-3. doi:10.1109/ICT.2005.1519922. 
[40] M.A. Ezzat, Theory of fractional order in generalized thermoelectric MHD, App/ Math Mode/ 35, 2011, 4965-4978, https://doi.org/10.1016/j.apm.2011.04.004.

[41] COMSOL Multiphysics. Flat Heat Pipe. Appl Gall 2018. https://uk.comsol.com/model/flat-heat-pipe-43841 (accessed February 13, 2019).

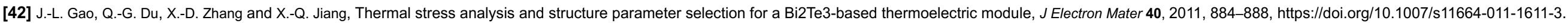

[43] E. Yin, Q. Li and Y. Xuan, Effect of non-uniform illumination on performance of solar thermoelectric generators, Front Energy 12, 2018, 239-248, https://doi.org/10.1007/s11708-018-0533-7.

[44] R.O. Suzuki, K.O. Ito and S. Oki, Analysis of the performance of thermoelectric modules under concentrated radiation heat flux, J Electron Mater 45, 2016, 1827-1835, https://doi.org/10.1007/s11664-015-4237-z.

Highlights

- Hybrid photovoltaic-thermoelectric systems with and without heat pipe are studied.

- Comparison of the photovoltaic only and hybrid photovoltaic systems is presented.

- Influence of concentration ratio, ambient temperature, wind speed is investigated.

- Three-dimensional numerical simulation using finite element method is presented.

\section{Queries and Answers}

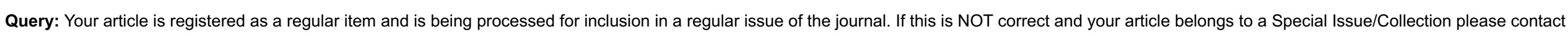
J.Shanmugam@elsevier.com immediately prior to returning your corrections.

Answer: Yes

Query: The author names have been tagged as given names and surnames (surnames are highlighted in teal color). Please confirm if they have been identified correctly. Answer: Yes

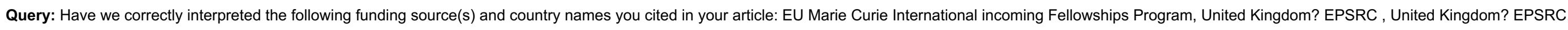
United Kingdom? Innovate UK, United Kingdom? I

Answer: Yes 